\title{
ROLE OF FLUID ON THE CONTACT DEFORMATION RESPONSE OF BIOLOGICAL TISSUE
}

\author{
Michael V. Swain ${ }^{a, b}$ \\ ${ }^{a}$ The University of Sydney, Faculty of Dentistry, Biomaterials Unit, AMME, Sydney NSW 2004, Australia \\ ${ }^{b}$ Don State Technical University, Biomechanics and biomaterials, Rostov-on Don, Russia \\ correspondence: michael.swain@sydney.edu.au
}

\begin{abstract}
This paper will focus on the role of fluids on the indentation deformation response of tooth and eye tissues. All natural biological materials contain fluid and function in a fluidic environment, which plays a critical role in responding to loading events as well as tissue nutrition. The location of this fluid varies and is considered as both bound and mobile with much of it located in cell compartments that are also able to respond directly to loading. The extent of the fluid content varies from less than $10 \%$ in the case of the highly mineralised enamel to more than $80 \%$ in the case of soft eye tissues. The role of the fluid and its response during loading is also complicated by the hierarchical structure of biological tissues, be they mineralised or not. The mechanisms by which the presence of fluid in these materials influences the mechanical response is still poorly understood and has not been systematically investigated. The present paper presents data generated over many years on both the above biological tissues and attempts to present indications as to the mechanism(s) by which the presence of fluid contributes to the deformation. The situation associated with contact loading with the presence of mobile fluid in the tissues results in a more complex situation than the classic elastic-plastic contact situation, but the latter still forms the basis for much of the analysis of instrumented indentation force-displacement load-unloading curves using various shapes of indenters, especially for mineralised structures. In the case of soft tissues the absence of agreed protocols for interpretation of force-displacement-time responses is restricting clinical/biological applications.
\end{abstract}

KEYwords: Biological tissues, fluid, indentation.

\section{INTRODUCTION}

Indentation tests provide a simple basis to interrogate the local mechanical behaviour of materials. The developments possible with the advent of computer based instruments over the past 50 years have enabled high precision force-displacement data to be generated with $\mathrm{nm}$ and $\mathrm{nN}$ precision [1,4]. While these instruments were primarily designed for classic elasticplastic materials, evermore widespread application to biological tissues has occurred especially over the past few decades [5]. In many instances minimal differences in test/instrument parameter requirements are necessary for conducting tests for instance in the case of tooth enamel. However, the situation for softer biological materials such as eye and soft organs generally is that the instrument requirements are very different from the original design applications of instrumented indentation machines. These instruments were initially developed to measure the properties of thin elastic/plastic/brittle films on classic engineering materials, which generally required high displacement resolution $(<\mathrm{nm})$ with reasonable forces $(10 \mathrm{mN})$. The situation for soft biological systems however is for very low loads $(<1 \mathrm{mN})$ and substantial displacements (up to $100 \mu \mathrm{m}$ ). Currently there are virtually no specific nano-indentation instruments developed for soft biological tissues and as such this community has had to adopt atomic force based systems for this purpose [5]. The limitations of both approaches often generates different outcomes when testing the same tissues, this arises because of the size of the required indenter, generally spherical tipped, for AFM versus nano-indenter systems [5]. The situation regarding software packages to assist with the interpretation of the resultant indentation force-displacement curves has become well advanced in the case of elastic/plastic and thin coating systems but this is not the case for biological soft tissues and associated materials [6] 8 ]. For the elastic/plastic community well defined ISO standards have been developed that enables the role of tip geometry and non-linear response to be addressed [6]. This unfortunately is not the situation for biological tissues. However, as Oyen has recently suggested, there is a consensus beginning to emerge as to viable approaches for interpreting the deformation response of soft tissues and structures [9]. In the case of interpretation of force-displacement behaviour, using a standard Berkovich diamond pyramid for elasticplastic materials, the ISO standard has been shown to be sufficiently robust as it utilises the basic Oliver and Pharr approach developed more than 25 years ago 6]. The outcomes from the incorporated software in the various instruments are the associated hardness and contact modulus. With specific assumptions this can be extended to the case of elastic/plastic thin 
films on various elastic/plastic substrates [10. More detailed outcomes for elastic/plastic materials such as the determination of the stress-strain, yield stress and work hardening have been empirically known for more than 60 years based upon the work of Tabor [11]. The use of spherical tipped indenters to quantify the nano-indentation response of elastic/plastic materials was pioneered by Field more than 25 years ago [12, 13. Details such as the role of work hardening and surface property gradients and their role on pile-up and sinking-in of the impression have limited the uptake of this approach although a recent study by Leitner et al [14] shows great progress in being able to match small pillar compression tests with nano-indentation test outcomes. As will be shown below in the case of teeth, the elastic/plastic analysis with pointed or spherical tipped indenters has provided considerable detail of the properties of enamel, dentine and as well as their diseased states (caries and molar incisor hyper-mineralisation) and in particular to their spatial variation [15-20. This information has been able to show a raft of outcomes relevant to the effect of clinical procedures, basic hierarchical size dependence and a basis to interpret creep [21-23]. However as will be shown below more critical recent ultrastructural analysis of teeth, especially for enamel, has led to the questioning of some of these outcomes [24]. In the case of soft tissues, with a focus on eye tissue, there are serious issues regarding what is the basis for the deformation observed. Eye tissue, like many soft gel systems, contain a very high percentage of fluid, up to $80 \%$, some of which can be considered bound and some mobile as elegantly illustrated by Oyen [9, 25]. However even with the bound fluid some of this may exist in cellular structures, which limit its general movement but does not prevent local displacement as the outer cell membranes are deformed. While gel like materials may be considered isotropic, biological tissues display hierarchical structure, which will result in likely scaling effects and in addition they have structural anisotropy 26. These latter features have evolved with organism development and are genuinely optimised for function with variations associated with species etc. The very high fluid content, the high degree of extensibility of such biological tissues plus their ability to fully recover limit the adequacy of current (elastic/plastic/viscoelastic) approaches to interpret the outcomes. There have been two major approaches for interpreting the outcomes (for soft tissues) of force-displacement response generated during testing of these structures; visco-elastic [27] and more recently poro-elastic [9]. The former considers the material as primarily a viscous body, which can be considered as equivalent to various spring and dashpot combinations or Prony series that are fitted to match the experimental outcomes [28]. Whereas the poroelastic approach considers the material to be bi- or multi-phasic with one phase being porous and continuous but behaving elastically while the other is fluid that must flow through the porous elastic structure as a consequence of a stress or pressure gradient [29]. The latter field was first introduced to soil mechanics by Darcy [30] and developed further by Biot 31. Application of poro-elastic behaviour of biological tissues was given a major boost by the work of Mow and colleagues who investigated the deformation response of cartilage tissue, especially of joints, using contact deformation [32, 33. Other investigations by Cowin et al explored the role of hierarchy on poro-elastic behaviour of bone under simple compression tests 34 . A relatively simple methodology to extract the various elastic components (4 for an isotropic material) and permeability of the body was developed by Galli and Oyen but involved an optimisation parameter fitting of a specific model that becomes slightly more complex when realistic loading rates are used to generate loading, then upon achieving max load, creep data [35, 36]. More recent strategies to determine the poroelastic response of gels have been developed by Lai and $\mathrm{Hu}$ [37] who have proposed the use of DMA systems involving frequency sweeps along with testing at different contact dimensions. This approach enables determination of whether visco-elastic or poro-elastic behaviour is the controlling mechanism as visco-elastic systems should be specimen or indenter size invariant while the fluid flow associated with poro-elastic behaviour is contact size dependent as deformation with the latter is related to fluid transport. There have also been novel approaches using fractional visco-elastic theory, which is somewhat easier to analytical model and invert than standard visco-elastic and poro-elastic solutions 38.

\section{AnAtomical ASPECtS}

\section{1. ТЕЕTH}

Figure 11 shows an overview of the anatomy of tooth tissue [39]. There are three major structural components, the outer external layer of enamel that is directly exposed to the oral cavity environment and is non-vital, the dentine which surrounds the pulp space which is vital and contains extensive innervation and fluid transport and in addition there is the cementum layer that connects the dentine in the root region of the tooth to the periodontal ligament that binds the tooth into the jaw. The focus here will be only on the enamel and dentine. The composition of the enamel layer shows hierarchical behaviour that is illustrated in Fig $1 \mathrm{p}$ and is predominately mineralized $85 \mathrm{vol} \%, 10$ vol\% fluid and 4 to $5 \mathrm{vol} \%$ residual proteins [40]. The smallest feature are the hydroxyapatite nanowires, approximately 25 by $50 \mathrm{~nm}$ in dimension that are also continuous from DEJ to the surface and are bundled into rods (approx. $5 \mathrm{\mu m}$ diameter) that form the second level of the hierarchy. These rods also are bundled into aligned groups called Hunter-Schreger bands that are some 50 to $100 \mu \mathrm{ms}$ in width that are readily observed on a polished surfaces of enamel that form the 3rd level of hierarchy [41, 42. 


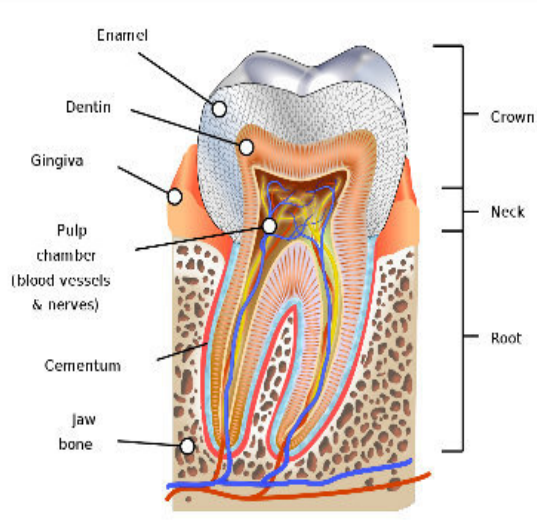

a)

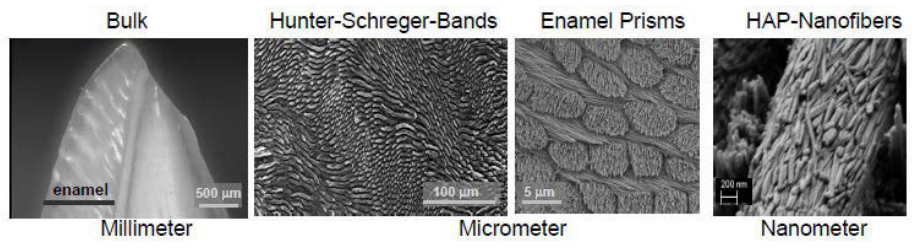

b)
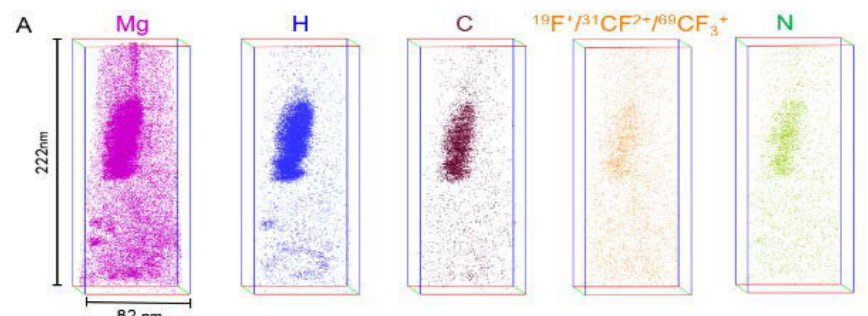

B

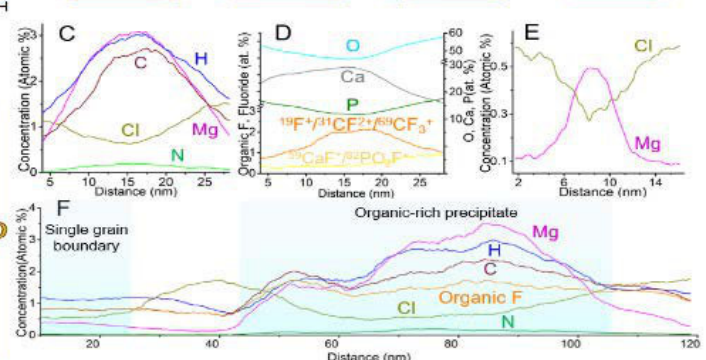

c)

FiguRE 1. a) Over-view of the structure of teeth [39. b) Hierarchical structure of enamel 42, and c) Atom probe tomography of enamel crystallites 43 .

There are also gradients in microstructural uniformity and composition as well as minor amounts of incorporated remnant proteins that increase from the surface to the dentine-enamel junction (DEJ). A more in-depth compositional analysis of enamel using atomic probe tomography also shows that the chemical composition of crystallites varies and that there are localised organic components present at some triple points as well as $\mathrm{Mg}$ rich amorphous lenses present in these locations 42. A typical illustration of the chemical composition of these structures is shown in Fig 17. Dentine is a no less complex structure than enamel as is illustrated in Fig 2. The hierarchy is more complex but consists of near unidirectional tubules aligned perpendicular to the dentine enamel junction that extend to the pulp. The density and size of the tubules increase towards the pulp from 0.5 to $1 \mu \mathrm{m}$ diameter. Surrounding these tubules is a mineral rich peri-tubular cuff approximately of 0.5 to $1 \mu \mathrm{m}$ thick, which also contains finer microtubules approx. 100 nm diameter normal to the axis of the main tubules and that extend through the mineralised cuff into the inter-tubular dentine. The latter region contains mineralised type IV collagen as well as fluid and rem- nant growth factors. The volume fraction of fluid is approximately $30 \mathrm{vol} \%$, while that of collagen IV is $20 \mathrm{vol} \%$ and mineralized tissue at $50 \mathrm{vol} \%$. Fluid is able to move within the dentine when loaded and this can trigger pain sensation from the enervation arrangement at the pulp and within the dentine [43].

Caries is the most prevalent affliction of humans and is associated with the development of acidic conditions from the fermentation of carbohydrates by various pathogens in the mouth [44. The formation of these acids in protected locations associated with difficulty of adequate oral hygiene results in acid induced demineralisation of tooth structure. Two common areas where these conditions occur and demineralisation results are about the fissures of molar teeth and the proximal space between teeth 45. Both areas are difficult for clinical detection often resulting in substantial extent of demineralisation including into the underlying dentine. The form of the demineralisation is very subtle, with this occurring at both the boundaries between rods and within individual crystallites in the rods of enamel 46. While in dentine dissolution of the minor tubules precedes that of the major tubules. Loss of mineral also occurs within the inter- 


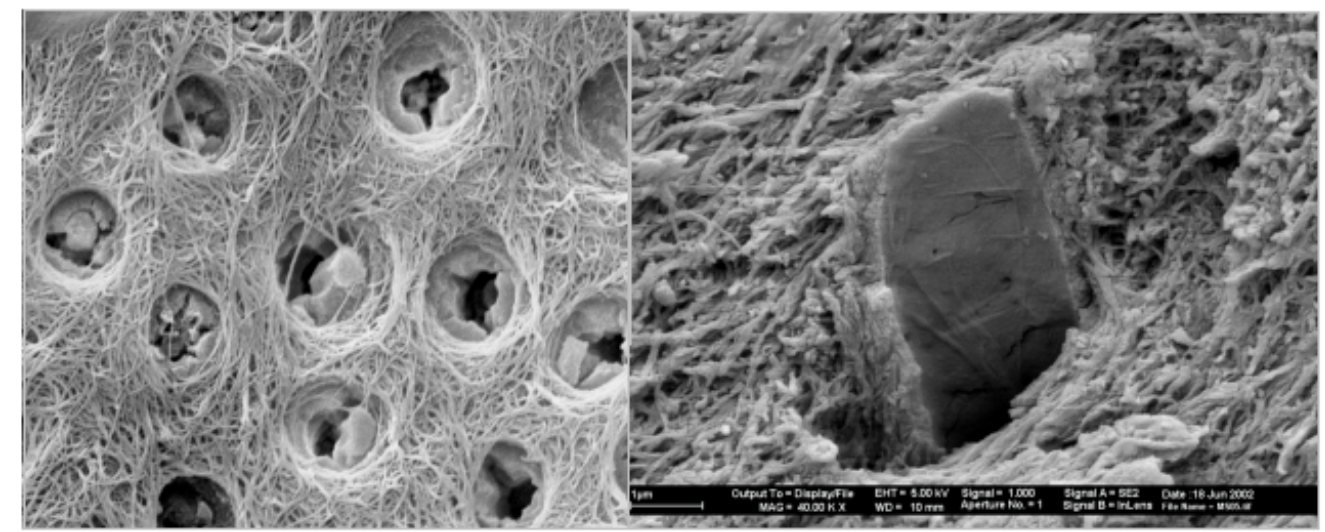

a)

FiguRE 2. Overview of the structure of dentine showing the complex tubule features as well as microtubules through the peri-tubular mineralised cuff.

tubular space. In the case of enamel there is often greater mineral loss beneath the surface with a harder surface layer present while in the case of dentine there is usually an almost linear gradient in mineral density from the surface with a hyper-mineralized region just in front of the active area of dissolution that is associated with the pulp/odontobast defence system, which deposits mineral occluding the tubules to prevent the migration of pathogens into the pulp space 47. Typical examples of demineralisation for enamel and dentine are shown in Fig 3 A plot of the mineral density of a proximal lesion in enamel is shown in Fig 4 which indicates that up to $50 \%$ loss of mineral occurs, yet the overall enamel structure remains intact. Note the small locations of mineral loss from within the cores of the tubules as well as at some triple point regions of crystallites. In the case of dentine (Fig $3 \mathrm{k}$ ) the loss of mineral results in a higher fluid content and partially degraded collagen that is much more permeable than sound dentine [48].

\subsection{EYES}

Here we shall only focus on the external surface of the eye namely the cornea, limbus and sclera regions which are shown in Figure 5 [51. The composition of eye tissue is predominantly fluid with collagen fibres and proteoglycans holding the collagen in specific arrangements to provide the optical clarity of the cornea and with partially permeable membranes restraining the fluid. The sclera and limbus regions are less well organised than the cornea and with slightly different volume fractions of liquid present. A high resolution cross-sectional view of cornea reveals the nature of the collagen fibre bundles that are aligned parallel to the surface resulting in an orthotropic structure with radial variations in the density and organisation of the fibers and the associated mechanical properties [50]. There are a range of degenerate diseases of the eye that influence the organisation of the collagen arrangement, which have a consequential outcome on the ability of the lens to focus images on the retina.

\subsection{OBSERVATIONS}

\subsubsection{TEETH}

Nano-indentation testing of enamel and dentine is very mature and was a focus of research shortly after the availability of high resolution indentation and AFM based systems [52. The analysis of force-displacement date followed that of elastic/plastic materials to enable the hardness and modulus to be estimated. Variations of $\mathrm{H}$ and $\mathrm{E}$ as a function of position identified gradients across enamel, dentine and higher resolution studies showed changes across the DEJ. A slightly different strategy was adopted by $\mathrm{He}$ et al, who as well as probing the variation of $\mathrm{H}$ and $\mathrm{E}$ spatially, used spherical tipped indenters to investigate the contact stress-strain response and observed that with such indenters non-linear behaviour began at very low contact stresses $(\mathrm{H} / 5)$ and was associated with substantial energy loss and hysteretic behaviour [53, 54]. This also agreed with the odd report that showed the apparent disappearance of indentations when viewed sometime after formation. He et al also found for enamel that both the initial loading behaviour and creep at max load and upon subsequent near complete unloading was dependent upon the environment with far less creep occurring for desiccated samples, see Fig 6 [55].

This behaviour was rationalised in terms of the role of the remnant proteins present in enamel because of their perceived presence surrounding all crystallites and ability to unfold and refold with the breaking and reformation of weak hydrogen bonds. An alternate approach to rationalise the creep of enamel was developed considering the behaviour as a series of spring and dashpots as well as plastic loss mechanisms [55] and also by considering enamel as a brick like structure held together by proteins which behave as a viscous component [58]. These two approaches are schematically shown in Fig 7] A more recent study has also shown that the hardness and friction response of enamel is dependent upon the fluid content with hardness increasing with desiccation while the friction 


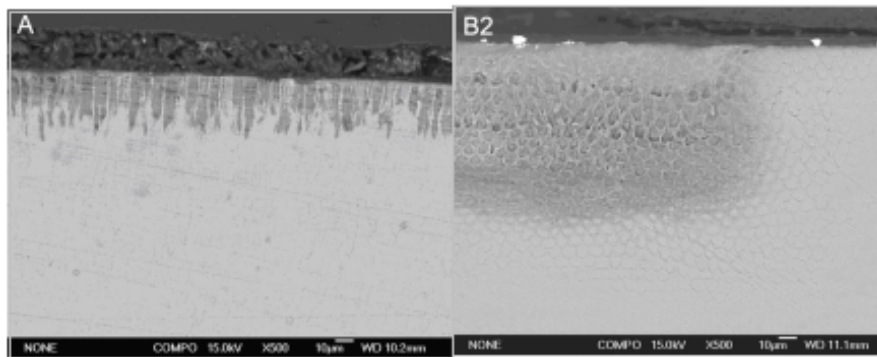

a) b)

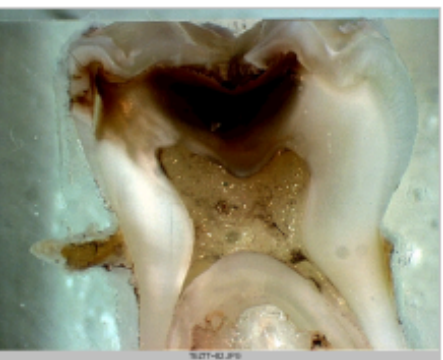

c)

FigurE 3. Backscattered SEM images of caries in enamel showing loss of mineral 49 both within the rods a) as well as at the inter-rods b). c) Optical image of cross-section of tooth with fissure caries showing the extensive subsurface demineralisation. Note the limited influence on the enamel [46].

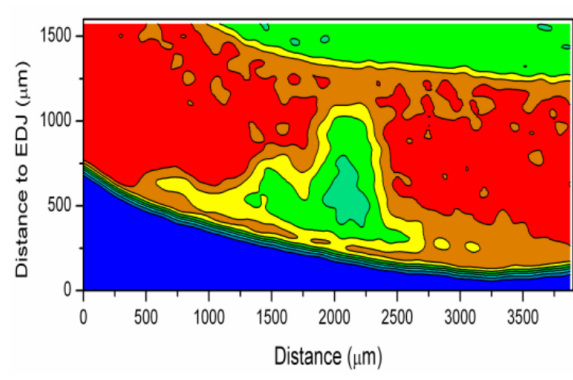

a)
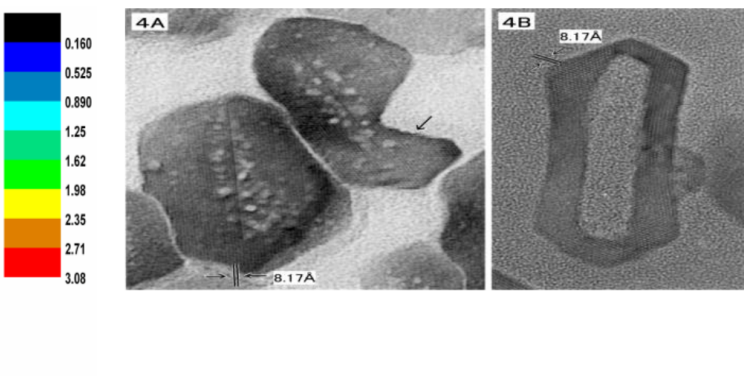

b)

Figure 4. a) MicroCT image of mineral density of enamel proximal white spot lesion [4], and (b) TEM observations of the manner in which mineral is lost at the nanoscale [50].

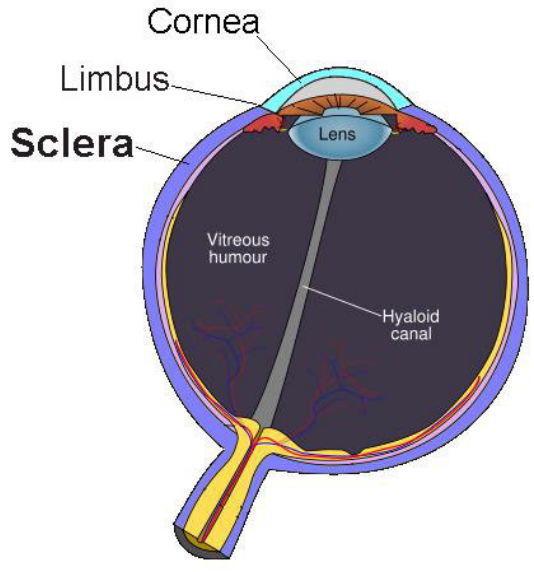

a)

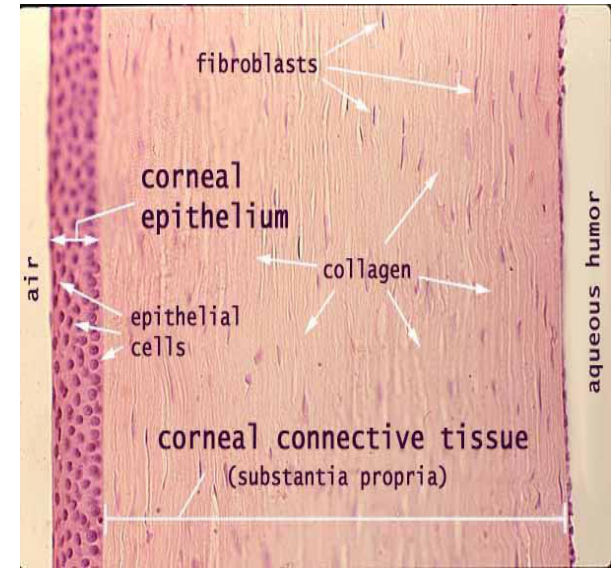

b)

Figure 5. a) Schematic illustration of a cross-section of an eye showing the various regions on the surface of the eye that are mentioned in the text [56]. b) Histology section of the cornea [57]

decreases with the presence of fluid as shown in Fig 8 [59].

The concept of crystallites of enamel being surrounded by protein and resulting in a hierarchical structure led to the development of an analysis rationalising the observed size dependent behaviour of the properties of enamel [61, 62. This approach was built upon the work of Ji and Gao which worked well for bone 63. With the advent of more recent Atom Probe Tomography [43] and HRTEM [24] work indicating the lack of a uniform protein/-peptide layer between crystallites has raised some questions as to the role of proteins on the resultant mechanical behaviour. An issue that has not been widely canvassed is the role of fluid transport, this is despite knowing that enamel typically contains up to $10 \mathrm{vol} \%$ fluid which is mobile. More than 3 decades ago Fox in a pioneering study found, during the cyclic loading of teeth at relatively low orally relevant loads, that considerable hysteresis occurred, which was loading rate and cation presence dependent [64]. Indentation tests by Bertassoni et al [65] as well as compression 


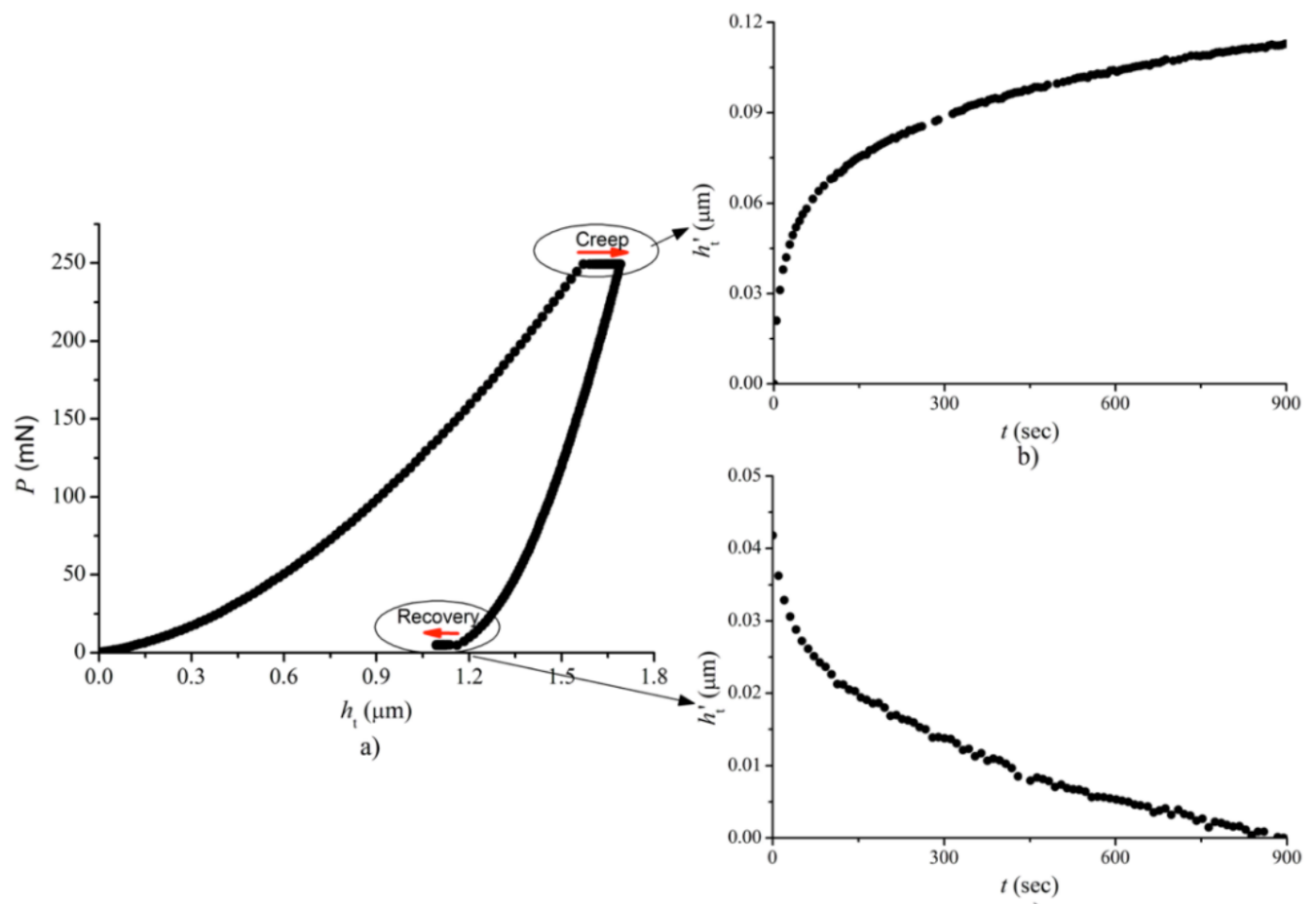

c)

FiguRE 6. Indentation force-displacement a) plus creep response of enamel b) at max load and c) at very low load ??

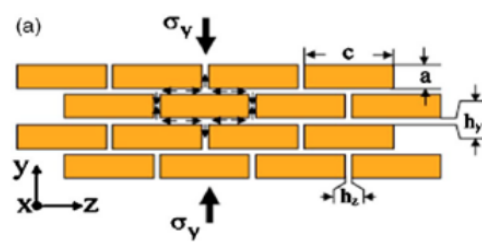

a)

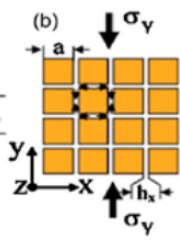

$\mathrm{C}_{0}, \mathrm{E}_{0} \quad \mathrm{Y}, \mathrm{H}_{0} \quad \mathrm{C}_{\mathrm{vp}}$
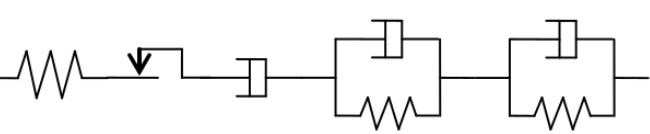

b)

FiguRE 7. Schematic illustrations of creep behaviour mechanisms for of enamel a) and b) Viscous fluid squeezed between rigid apatitie crystals [58] and c) Viscoelastic-plastic body "spring + plastic element + dashpot +2 Kelvin-Voigt bodies" [55].
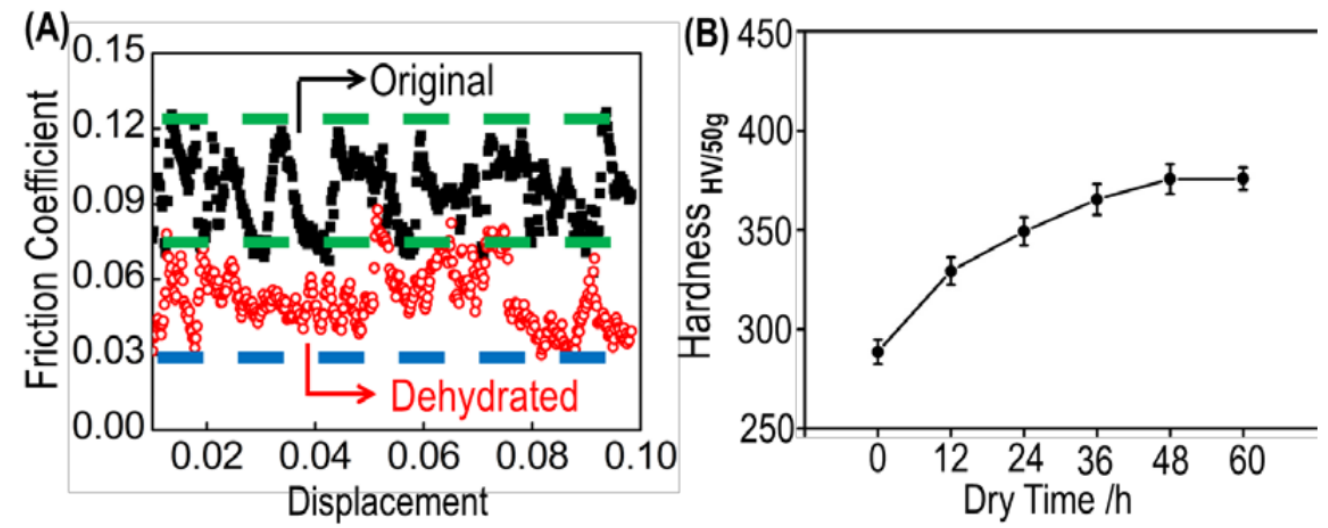

FiguRE 8. Observations of a) friction coefficient of enamel wet vs dry, and b) Hardness of enamel with dehydration time [59].

tests [66] of dentine also displayed creep at maximum load. The former authors showed that the presence of proteoglycans also influenced the extent of creep and subsequent recovery. These authors, like the earlier studies of enamel [54, suggested that the creep response of dentine was influenced by the presence of proteins. It is also known that both enamel and dentine are permeable with minor amounts of fluid from the pulp exiting into the oral cavity. The permeability of dentine, with its high density of open tubules, is 


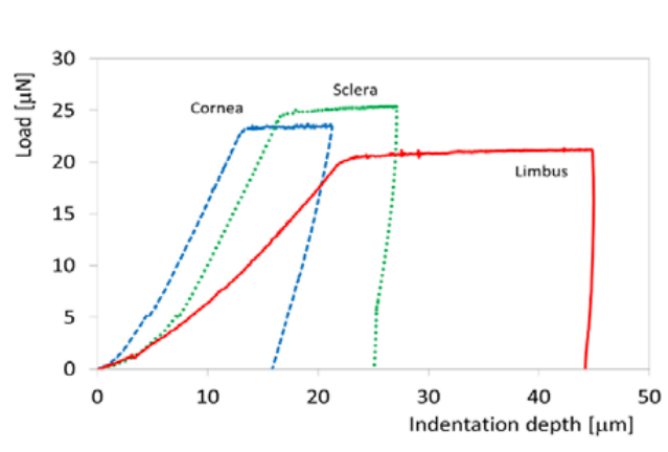

a)

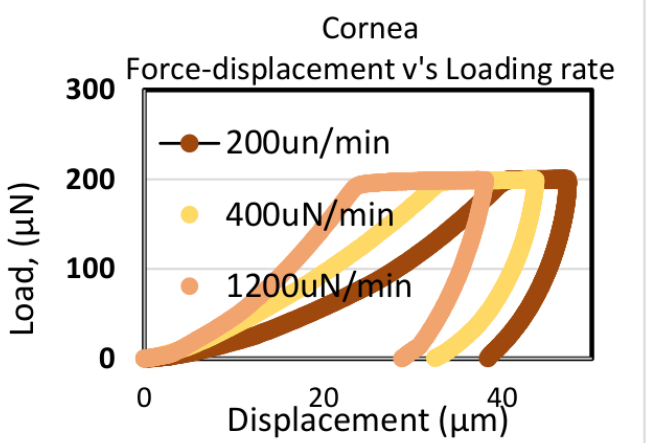

b)

FiguRE 9. Force-displacement curves during the indentation of various regions of the external surface of the eye 60. These force-displacement curves are also strongly loading rate dependent.

greater than enamel and both tissues show increased permeability when caries is present. In fracture tests on dentine 43 it was found that the presence of fluid played a major role in the fracture toughness and was observed to be drawn into the tubules in the tensile stress region about the crack tip but was expelled from tubules after the passage of the crack tip, that is in the wake of the crack tip. In another study it was found that in flexure tests of dentine beams the flexural behaviour including the strength and nominal E modulus was strain rate dependent for fluid filled but not for dehydrated samples [67]. Caries has a major influence on the deformation behaviour of enamel and dentine. The extent of mineral loss in teeth is best illustrated using micro Computed Tomography $(\mathrm{mCT})$ as shown in Fig 4 for a proximal lesion in enamel. As shown in studies by Huang et al this loss of mineral has a major influence on nano-indentation derived hardness and elastic modulus properties 68. The interpretation of the force-displacement curves for the latter outcomes was based upon the assumption of elastic-plastic behaviour whereas the behaviour of highly porous materials, which are generally fluid filled. The latter is far more complex involving both fluid displacement and crushing or densifying the porous structure directly beneath the indenter tip as shown by studies of porous bioceramics [69] and fitted the failure criterion proposed by Gurson et al [70]. To date the motion of fluid transport within such a porous structure has not been addressed. In the case of carious dentine it was observed that there was a significant difference in the behaviour of saturated versus dehydrated specimens [71]. These authors also noted that the force-displacement response of fluid filledhighly demineralised dentine showed a substantial recovery during unloading, presumably associated with fluid flow returning to the consolidated material beneath the area of contact.

\subsubsection{EYE RESULTS}

Indentation tests on eye tissues have become popular over the past decade, especially with the ability to use
AFM systems with small spherical tipped indenters $(\mathrm{R}<20 \mu \mathrm{m})$ [72]. Nano-indentation tests have also been conducted but have required systems with low force but large displacement using relatively large indenter spherical tips $(\mathrm{R} \sim 500 \mu \mathrm{m})$ [60, 73]. The AFM approach has typically involved rapid load/unload tests and relied upon Hertzian contact analysis for the determination of the elastic modulus. Whereas the nano-indentation tests usually involve a slower loading rate and incorporate a hold period at max load generating substantial creep response, see Fig 9 . Interpretation of NI results for eyes based upon an inverse FEA visco-elastic analysis has been conducted by Abyaneh et al 73 . An alternate highly simplified poro-elastic approach developed by the author and colleagues [60] considers localised deformation of these highly fluid filled tissues as being determined by the collagen elastic response and movement of fluid caused by indentation induced transient pressure gradients. At longer hold times at max load the resultant displacement is determined by the elastic properties of the structure whereas the short term behaviour is dependent upon the loading rate and hydraulic conductivity. The aim of the latter approach was an attempt to develop an output, namely an effective $\mathrm{E}$ and effective hydraulic conductivity $\mathrm{K}$, that was comparable to the hardness and contact modulus that has so successfully been used for elastic/plastic materials. These effective $\mathrm{E}$ and $\mathrm{K}$ values are recognised as approximations because as outlined above eye tissues are highly anisotropic with orthotropic mechanical properties because of the aligned collagen fibres parallel to the surface, they have gradients in collagen density and are likely to have orthotropic hydraulic conductivity parameters.

\section{Conclusions}

The presence of fluid plays a significant role in the deformation response of biological tissues. In this overview only two types of tissue are considered, namely highly mineralised tooth tissue and highly fluid containing eye tissue. In both instances there is 
clear evidence of the influence of fluid but the mechanisms are not well understood. There is a clear necessity for further critical investigations to understand the mechanisms responsible in these and other biological tissues. Of even greater need is for collective agreement as to an approach to interpret the force-displacement-time curves generated during the indentation of such complex tissues.

\section{ACKNOWLEDGEMENTS}

The author wishes to thank his many colleagues who have been part of this journey investigating the indentation responses of teeth and eyes. Also Australian Research Council (ARC DP160104602 and LP180101352) plus the Government of the Russian Federation (grant No. 14.Z50.31.0046).

\section{REFERENCES}

[1] S. Bulychev, V. Alekhin, M. Shorshorov, et al. Determining young's modulus from the indentor penetration diagram. Ind Lab (USSR) 41:1409-1412, 1975.

[2] G. N., P. M. A. Cox J. M. Philosophical magazine 22:881-891, 1970.

[3] T. J. Bell, A. Bendeli, J. S. Field, et al. The determination of surface plastic and elastic properties by ultra micro-indentation. Metrologia 28(6):463-469, 1991. DOI:10.1088/0026-1394/28/6/004

[4] C. Perrott. Elastic-plastic indentation: Hardness and fracture. Wear 45(3):293 - 309, 1977. DOI:10.1016/0043-1648(77)90021-7

[5] E. Rettler, S. Hoeppener, B. W. Sigusch, U. S. Schubert. Mapping the mechanical properties of biomaterials on different length scales: depth-sensing indentation and afm based nanoindentation. J Mater Chem B 1:2789-2806, 2013. DOI:10.1039/C3TB20120A

[6] G. Pharr, W. Oliver. Measurement of thin film mechanical properties using nanoindentation. MRS Bulletin 17(7):28 - 33, 1992. DOI:/10.1557/S0883769400041634.

[7] ISO 14577. ISO standard metallic materials, 2002.

[8] Asmech Technology Pte Ltd. Asmech GmbH Advanced Surface Mechanics Germany, 2003.

[9] M. L. Oyen. Nanoindentation of hydrated materials and tissues. Current Opinion in Solid State and Materials Science 19(6):317 - 323, 2015. Recent Advances in Nanoindentation, DOI:10.1016/j.cossms.2015.03.001

[10] J. Menčík, D. Munz, E. Quandt, et al. Determination of elastic modulus of thin layers using nanoindentation. Journal of Materials Research 12:2475 - 2484, 1997. DOI:10.1557/JMR.1997.0327

[11] D. D. Tabor. The hardness of metals. Oxford : Clarendon Press ; New York : Oxford University Press, 2000. Originally published: Oxford : Clarendon Press, 1951.

[12] J. Field, M. Swain. A simple predictive model for spherical indentation. Journal of Materials Research 8(2):297-306, 1993. DOI:10.1557/JMR.1993.0297
[13] J. Field, M. Swain. Determining the mechanical properties of small volumes of material from submicrometer spherical indentations. Journal of Materials Research 10(1):101-112, 1995. DOI:10.1557/JMR.1995.0101.

[14] A. Leitner, V. Maier-Kiener, D. Kiener. Essential refinements of spherical nanoindentation protocols for the reliable determination of mechanical flow curves. Materials \& Design 146:69 - 80, 2018. DOI:10.1016/j.matdes.2018.03.003

[15] L. H. He, N. Fujisawa, M. V. Swain. Elastic modulus and stress-strain response of human enamel by nano-indentation. Biomaterials 27(24):4388 - 4398, 2006. DOI:10.1016/j.biomaterials.2006.03.045.

[16] L. Angker, M. Swain. Nanoindentation: Application to dental hard tissue investigations. Journal of Materials Research 21(8):1893-1905, 2006. DOI:10.1557/jmr.2006.0257.

[17] E. K. Mahoney, N. M. Kilpatrick, M. V. Swain. Behaviour of primary incisor caries: a micromechanical study. International Journal of Paediatric Dentistry 16(4):270-277, 2006. https://onlinelibrary.wiley. com/doi/pdf/10.1111/j.1365-263X.2006.00748.x DOI:10.1111/j.1365-263X.2006.00748.x

[18] J. Cuy, A. Mann, K. Livi, et al. Nanoindentation mapping of the mechanical properties of human molar tooth enamel. Archives of Oral Biology 47(4):281-291, 2002. DOI:10.1016/S0003-9969(02)00006-7

[19] E. K. Mahoney, R. Rohanizadeh, F. Ismail, et al. Mechanical properties and microstructure of hypomineralised enamel of permanent teeth. Biomaterials 25(20):5091 - 5100, 2004. Focus on Biomaterials Science in Australia, DOI:10.1016/j.biomaterials.2004.02.044

[20] Z.-H. Xie, E. Mahoney, N. Kilpatrick, et al. On the structure-property relationship of sound and hypomineralized enamel. Acta Biomaterialia 3(6):865 872, 2007. DOI:10.1016/j.actbio.2007.05.007

[21] S. F. Ang, E. L. Bortel, M. V. Swain, et al. Size-dependent elastic/inelastic behavior of enamel over millimeter and nanometer length scales. Biomaterials 31(7):1955 - 1963, 2010. DOI:10.1016/j.biomaterials.2009.11.045

[22] J. Menčík, L. H. He, M. V. Swain. Determination of viscoelastic-plastic material parameters of biomaterials by instrumented indentation. Journal of the Mechanical Behavior of Biomedical Materials 2(4):318 - 325, 2009. Nanoindentation of Biological Materials, DOI:10.1016/j.jmbbm.2008.09.002

[23] S. Bechtle, S. F. Ang, G. A. Schneider. On the mechanical properties of hierarchically structured biological materials. Biomaterials 31(25):6378 - 6385, 2010. DOI:10.1016/j.biomaterials.2010.05.044.

[24] J. Koldehoff, M. V. Swain, G. A. Schneider. The geometrical structure of interfaces in dental enamel: A fib-stem investigation. Acta Biomaterialia 2020. DOI:10.1016/j.actbio.2019.12.040

[25] M. L. Oyen, T. A. Shean, D. G. Strange, M. Galli. Size effects in indentation of hydrated biological tissues. Journal of Materials Research 27(1):245-255, 2012. DOI:10.1557/jmr.2011.322 
[26] L. Cardoso, S. C. Cowin. Role of structural anisotropy of biological tissues in poroelastic wave propagation. Mechanics of Materials 44:174 - 188, 2012. Microstructures and Anisotropies, DOI:10.1016/j.mechmat.2011.08.007.

[27] A. Maccabi, A. Shin, N. K. Namiri, et al. Quantitative characterization of viscoelastic behavior in tissue-mimicking phantoms and ex vivo animal tissues. PLOS ONE 13(1):1-18, 2018. DOI:10.1371/journal.pone.0191919

[28] I. Argatov, G. Mishuris. Indentation of a Poroelastic/Biphasic Half-Space, pp. 285-321. 2018. DOI:10.1007/978-3-319-78533-2_11

[29] M. A. Biot. General theory of three-dimensional consolidation. Journal of Applied Physics 12(2):155-164, 1941. 10.1063/1.1712886 DOI:10.1063/1.1712886

[30] A. Mak, W. Lai, V. Mow. Biphasic indentation of articular cartilage-i. theoretical analysis. Journal of Biomechanics 20(7):703 - 714, 1987. DOI:10.1016/0021-9290(87)90036-4

[31] V. C. Mow, S. C. Kuei, W. M. Lai, C. G. Armstrong. Biphasic Creep and Stress Relaxation of Articular Cartilage in Compression: Theory and Experiments. Journal of Biomechanical Engineering 102(1):73-84, 1980. https:

//asmedigitalcollection.asme.org/biomechanical/ article-pdf/102/1/73/5512714/73_1.pdf DOI:10.1115/1.3138202

[32] M. Galli, M. Oyen. Fast identification of poroelastic parameters from indentation tests. Computer Modeling in Engineering and Sciences (CMES) 48, 2009. DOI:10.3970/cmes.2009.048.241

[33] E. Bonnevie, V. Baro, L. Wang, D. Burris. Fluid load support during localized indentation of cartilage with a spherical probe. Journal of Biomechanics 45(6):1036 1041, 2012. DOI:10.1016/j.jbiomech.2011.12.019.

[34] G. Gailani, M. Benalla, R. Mahamud, et al. Experimental Determination of the Permeability in the Lacunar-Canalicular Porosity of Bone. Journal of Biomechanical Engineering 131(10), 2009. 101007, https :

//asmedigitalcollection.asme.org/biomechanical/ article-pdf/131/10/101007/5543496/101007_1.pdf DOI:10.1115/1.3200908

[35] S. C. Cowin. Bone poroelasticity. Journal of Biomechanics 32(3):217 - 238, 1999. DOI:10.1016/S0021-9290(98)00161-4

[36] Y. Hu, X. Zhao, J. Vlassak, Z. Suo. Using indentation to characterize the poroelasticity of gels. Applied Physics Letters 96(12), 2010. DOI:10.1063/1.3370354

[37] Y. Lai, Y. Hu. Unified solution for poroelastic oscillation indentation on gels for spherical, conical and cylindrical indenters. Soft matter 13(4):852-861, 2017.

[38] R. Shahsavari, F.-J. Ulm. Indentation analysis of fractional viscoelastic solids. Journal of Mechanics of materials and Structures 4(3):523-550, 2009.

[39] National library of medicine. http://www.nlm.nih. gov/medlineplus/ency/imagepages/1121.htm. Accessed: 2019-12-30.
[40] J. K. Avery, P. F. Steele, N. Avery. Oral development and histology. Thieme, 2002.

[41] A. R. A. R. Ten Cate. Oral histology : development, structure, and function. St. Louis : Mosby, 5th edn., 1998. Includes bibliographical references and index.

[42] E. D. Yilmaz, G. A. Schneider, M. V. Swain. Influence of structural hierarchy on the fracture behaviour of tooth enamel. Philosophical Transactions of the Royal Society A: Mathematical, Physical and Engineering Sciences 373(2038):20140130, 2015.

[43] A. La Fontaine, A. Zavgorodniy, H. Liu, et al. Atomic-scale compositional mapping reveals mg-rich amorphous calcium phosphate in human dental enamel. Science advances 2(9):e1601145, 2016.

[44] B. Kahler, M. V. Swain, A. Moule. Fracturetoughening mechanisms responsible for differences in work to fracture of hydrated and dehydrated dentine. Journal of biomechanics 36(2):229-237, 2003.

[45] E. Kidd. Essentials of Dental Caries. Oxford University Press, 4th edn., 2016.

[46] L. Angker, M. V. Swain, N. Kilpatrick. Characterising the micro-mechanical behaviour of the carious dentine of primary teeth using nano-indentation. Journal of Biomechanics 38(7):1535-1542, 2005.

[47] T. T. Huang, A. S. Jones, L. H. He, et al. Characterisation of enamel white spot lesions using x-ray micro-tomography. Journal of dentistry 35(9):737-743, 2007.

[48] J. Xue, W. Li, M. V. Swain. In vitro demineralization of human enamel natural and abraded surfaces: a micromechanical and sem investigation. Journal of dentistry 37(4):264-272, 2009.

[49] T. Yanagisawa, Y. Miake. High-resolution electron microscopy of enamel-crystal demineralization and remineralization in carious lesions. Microscopy 52(6):605-613, 2003.

[50] A. V. Zavgorodniy, R. Rohanizadeh, M. V. Swain. Ultrastructure of dentine carious lesions. Archives of oral biology 53(2):124-132, 2008.

[51] Bright focus foundation. https://www.brightfocus org/macular-glaucoma/infographic/anatomy-eye Accessed: 2019-12-30.

[52] L. H. He, N. Fujisawa, M. V. Swain. Elastic modulus and stress-strain response of human enamel by nano-indentation. Biomaterials 27(24):4388-4398, 2006.

[53] L. H. He, M. V. Swain. Nanoindentation derived stress-strain properties of dental materials. Dental materials 23(7):814-821, 2007.

[54] L. H. He, M. V. Swain. Towards automated 3d finite element modeling of direct fiber reinforced composite dental bridge. Journal of Biomedical Materials Research Part B: Applied Biomaterials 81A:484-489, 2007.

[55] J. Menčík, L. H. He, M. V. Swain. Determination of viscoelastic-plastic material parameters of biomaterials by instrumented indentation. Journal of the Mechanical Behavior of Biomedical Materials 2(4):318 - 325, 2009. Nanoindentation of Biological Materials, DOI:10.1016/j.jmbbm.2008.09.002 
[56] D. G. Dawson, M. A. Watsky, D. H. Geroski, H. F. Edelhauser. Chapter 4 cornea and sclera. 2009.

[57] S. Habelitz, S. Marshall, G. Marshall Jr, M. Balooch. Mechanical properties of human dental enamel on the nanometre scale. Archives of Oral Biology 46(2):173-183, 2001.

[58] M. Swain, S. Michael, L. Thai, P. Lucas. Influence of indenter geometry on the frictional sliding resistance of tooth enamel. Biosurface and Biotribology 3(4):224-237, 2017.

[59] L. Hua, W. Wang, M. Swain, et al. The dehydration effect on mechanical properties of tooth enamel. Journal of the Mechanical Behavior of Biomedical Materials 95:210 - 214, 2019. DOI:10.1016/j.jmbbm.2019.04.013.

[60] M. Swain, J. Nohava, P. Eberwein. A simple basis for determination of the modulus and hydraulic conductivity of human ocular surface using nano-indentation. Acta biomaterialia 50:312-321, 2017.

[61] S. Bechtle, H. Özcoban, E. T. Lilleodden, et al. Hierarchical flexural strength of enamel: transition from brittle to damage-tolerant behaviour. Journal of The Royal Society Interface 9(71):1265-1274, 2012.

[62] S. F. Ang, E. L. Bortel, M. V. Swain, et al. Size-dependent elastic/inelastic behavior of enamel over millimeter and nanometer length scales. Biomaterials 31(7):1955-1963, 2010.

[63] B. Ji, H. Gao. Mechanical properties of nanostructure of biological materials. Journal of the Mechanics and Physics of Solids 52(9):1963-1990, 2004.

[64] P. Fox. The toughness of tooth enamel, a natural fibrous composite. Journal of Materials Science 15(12):3113-3121, 1980.

[65] L. E. Bertassoni, M. V. Swain. Influence of hydration on nanoindentation induced energy expenditure of dentin. Journal of biomechanics 45(9):1679-1683, 2012.

[66] X. Wang, J. Zhou, D. Kang, et al. The bulk compressive creep and recovery behavior of human dentine and resin-based dental materials. Dental Materials 2020. DOI:10.1016/j.dental.2020.01.003
[67] D. Arola, W. Zheng. Hydration and dynamic fatigue of dentin. Journal of Biomedical Materials Research Part A: An Official Journal of The Society for Biomaterials, The Japanese Society for Biomaterials, and The Australian Society for Biomaterials and the Korean Society for Biomaterials 77(1):148-159, 2006.

[68] T. Huang, L. He, M. Darendeliler, M. Swain. Nano-indentation characterisation of natural carious white spot lesions. Caries research 44(2):101-107, 2010.

[69] S. Meille, M. Gallo, P. Clément, et al. Spherical instrumented indentation as a tool to characterize porous bioceramics and their resorption. Journal of the European Ceramic Society 39(15):4459-4472, 2019.

[70] A. L. Gurson. Continuum theory of ductile rupture by void nucleation and growth: Part i-yield criteria and flow rules for porous ductile media 1977.

[71] S. Meille, M. Gallo, P. Clément, et al. Spherical instrumented indentation as a tool to characterize porous bioceramics and their resorption. Journal of the European Ceramic Society 39(15):4459-4472, 2019.

[72] J. A. Last, S. J. Liliensiek, P. F. Nealey, C. J. Murphy. Determining the mechanical properties of human corneal basement membranes with atomic force microscopy. Journal of structural biology 167(1):19-24, 2009.

[73] M. Abyaneh, R. Wildman, I. Ashcroft, P. Ruiz. A hybrid approach to determining cornea mechanical properties in vivo using a combination of nanoindentation and inverse finite element analysis. Journal of the Mechanical Behavior of Biomedical Materials 27:239 - 248, 2013. DOI:10.1016/j.jmbbm.2013.05.016 